\title{
Oridonin, an AKT1 Inhibitor, Suppresses the Growth of Breast Cancers with Hyperactivation of PI3K/AKT Signaling
}

\author{
Xin-Yu Liu ${ }^{1}$, Lizi Zhang ${ }^{1 *}$ \\ ${ }^{1}$ School of Clinical Medicine, Weifang Medical University, Weifang 261053, Shandong, China
}

\begin{abstract}
Purpose: The study investigates the therapeutic effect of Oridonin on PTEN loss and HER2 amplification PI3K/AKT signaling hyper-activated (p-AKTHigh) breast cancer. Methods: The experiment uses MDAMB231, MCF-10A, SKBR3 (HER2 amplification), MDAMB468 (PTEN loss) cells, and Xenograft Murine Models. Cell viability is assessed by MTT, Clonogenic growth, CCK- 8 assays. The inhibition of phosphorylation is tested by Western blot. Xenograft studies are used to test tumor growth blockage. The most possible result: Oridonin inhibits phosphorylation of AKT1 substrates and downstream proteins instead of AKT1. Also, it blocks the growth of PTEN loss and HER2 amplification p-AKTHigh breast cancer. Conclusion: This study provides important information for the clinical trial of Oridonin. Future experiments should focus on its toxicity and efficacy.
\end{abstract}

\section{Introduction}

Phosphoinositide 3-kinase (PI3K) pathway is closely related to several key cellular functions like cell proliferation [1]. The abnormal activation of PI3K is opposed by PTEN, a tumor suppressor. Once PTEN is lost, PI3K activators such as RTKs, a kind of growth factor receptor are activated and stimulate phosphatidylinositol 4,5-trisphosphate (PIP2) to generate PIP3. With this, AKT and downstream activators are stimulated. PI3K/AKT pathway is also boosted by overexpression of growth factor receptor [2]. 15\%-20\% breast tumors are caused by constitutively activated RTK [3]. Mutated PIK3CA gene has been reported to encode p $110 \alpha$ isoform of PI3K, observed in over $25 \%$ breast tumors [4]. Deletion of PTEN occurs in $25 \%$ breast cancers [5].

Breast cancer is reported to be a severe disease [6] [7]. Formal inhibitors used to treat breast cancer are either too toxic or have unsatisfactory results [8]. Thus, there is a large need to discover new drugs. Many researchers have focused on traditional Chinese medicinal plants [9]. Sun et al screened 441 traditional Chinese medicinal plant extracts by the cell viability assay. The most effective molecule among 441 is Oridonin, a potential anti-cancer compound in variety of cancer cells [10].

This study is designed to test the therapeutic efficiency of Oridonin, in the treatment of p-AKTHigh in vivo and vitro. And it also predicts that Orodonin is an inhibition of AKT1 which activates PRAS40 and downstream protein S6RP.

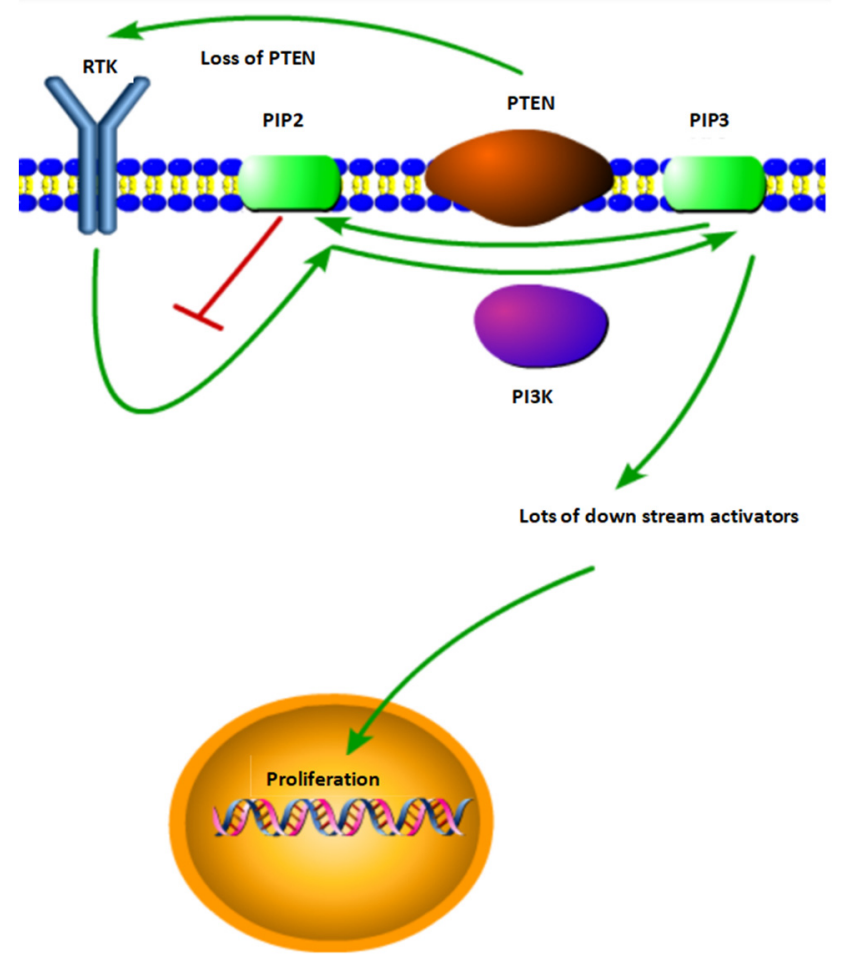

Fig.1. Part of PI3K/AKT signaling pathway related to the growth of breast cancer: PTEN helps to inhibit phosphorylation of PIP2 to PIP3 and downstream activators. Once PTEN is mistakenly deleted, RTK will be activated and boost the phosphorylation of PIP2 to PIP3 and downstream activators.

\section{Methods}

The experiment requires p-AKTHigh cell lines (SKBR3, MDAMB468), low levels of AKT phosphorylation (p-AKTLow) cell lines (MDAMB231 and MCF-10A), 
proved exceptionally effective $\mathrm{PI} 3 \mathrm{~K} / \mathrm{mTOR}$ dual inhibitor BEZ235and DMSO as the positive and negative control, as well as Oridonin.

All major materials the study needs are listed in Table 1.

Table 1. Major materials used in this experiment

\begin{tabular}{|l|l|}
\hline Materials & Applications or features \\
\hline $\begin{array}{l}\text { MDAMB231 } \\
\text { cells }\end{array}$ & p-AKT \\
\hline MCF-10A cells & p-AKT $^{\text {Low }}$ \\
\hline $\begin{array}{l}\text { MDAMB468 } \\
\text { cells }\end{array}$ & p-AKT $^{\text {High }}$, PTEN loss \\
\hline SKBR3 cells & $\begin{array}{l}\text { p-AKT }^{\text {High }} \text {, HER2 } \\
\text { amplification }\end{array}$ \\
\hline $\begin{array}{l}\text { athymic } \\
\text { nude-Foxn } 1^{\text {nu }}\end{array}$ & $\begin{array}{l}\text { Construction of breast } \\
\text { cancer mice model }\end{array}$ \\
\hline Oridonin & $\begin{array}{l}\text { Experimental } \\
\text { compound }\end{array}$ \\
\hline BEZ235 & Positive control \\
\hline
\end{tabular}

\subsection{Cell culture}

$10 \%$ fetal bovine serum (FBS) is used to cultivate MDAMB231 and MCF-10A cells. RPMI1640 with 10\% FBS is used to keep SKBR3 cells. MDAMB468 cells is kept in DMEM/H with $10 \%$ FBS. They are all kept at $37^{\circ} \mathrm{C}$ in $5 \% \mathrm{CO}_{2}$.

\subsection{MTT Assay}

Equal numbers of MDAMB231, MCF-10A, SKBR3, and MDAMB468 cells are plated in 96-well plates. All of them are cultivated with a variety of concentrations of Oridonin and BEZ235 for 72 hours. After cultivation, MTT $(0.5 \mathrm{mg} / \mathrm{ml})$ will be added and co-incubating for 4 hours. Then, DMSO will be plated into each well. CellTiter-Glo luminescent cell viability assay will be used to assess.

\subsection{Clonogenic growth assays}

Equal numbers of MDAMB231, MCF-10A, SKBR3, and MDAMB468 cells are plated in 6-well plates and are equally divided into 3 groups. BEZ235 $(250 \mathrm{nM})$ is positive control, DMSO is Vehicle control, and Oridonin $(1 \mu \mathrm{M})$ is used in experimental group. All groups are kept for 3 weeks and then stained by crystal violet. CellTiter-Glo luminescent cell viability assay to assess.

\subsection{CCK-8 assay}

Equal numbers of MDAMB231, MCF-10A, SKBR3, MDAMB468 are plated in 96-well plates. They are cultivated for 24 hours and separated into 2 groups. After that, add BEZ235 $(250 \mathrm{nM})$ to one group and Oridonin to another $(1 \mathrm{mM})$. Then co-incubate for 24 hours. Finally, each well is added $10 \mu \mathrm{L} \mathrm{CCK}-8$ and incubate for 2 hours. The multifunction microplate reader will be used to measure.

\subsection{Western blotting}

MDAMB468 and SKBR3 cells are starved for 2 hours and equally separated into 3 groups. 1 hour before immunoblotting, DMSO or 0.1 and 1 M Oridonin or 50 and $250 \mathrm{nM}$ BEZ235 are used to treat three groups cells. All cells are washed with icy PBS trice and then laysed by $1 \%$ NP-40 buffer supplemented with protease and phosphatase inhibitors. SDS-PAGE is used to resolve 30 micrograms of total lysates. Nitrocellulose membranes transferring will follow. The primary antibodies are for p-PRAS40, p-AKT, p-S6RP, and AKT. The secondary antibodies are anti-mouse and fluorophore-conjugated anti-rabbit IgG. All membranes hybridize with antibodies above successively in $1 \%$ non-fat milk. Odyssey scanner will be used to detect.

\subsection{Xenograft studies}

Athymic nude-Foxn $1^{\text {nu }}$ mice are given 1 week to adjust to new environment. Inject cells $(100 \mathrm{~L})$ into each site of mammary fat pads. Tumors are measured in two-dimension and Volume $=0.5 \times$ length $\times$ width $\times$ Width. Tumors are measured once every 3 days. After 24 days, tumors will be cut and kept in formalin overnight and then in $70 \%$ ethanol to do histopathology analysis.

Mice take oridonin $(15 \mathrm{mg} / \mathrm{kg})$ vehicle daily by intraperitoneal injectionand. BEZ235 $45 \mathrm{mg} / \mathrm{kg}$ daily by oral gavage.

\subsection{Statistical analyses}

All data is analyzed by Student's t-test, and $\mathrm{p}<0.05$ will be taken into consideration in statistically significant.

\section{Results}

\subsection{MTT, CCK-8, and Clonogenic growth assays}

\subsubsection{Possible result 1}

Cell viability of $\mathrm{p}-\mathrm{AKT}^{\text {High }}$ cell lines are all suppressed both in Oridonin and BEZ235 but not in vehicle control. That of $\mathrm{p}-\mathrm{AKT}^{\mathrm{Low}}$ cell lines shows no significant suppression in all groups.

\subsubsection{Possible result 2}

Cell viability of $\mathrm{p}-\mathrm{AKT}^{\mathrm{Low}}$ cell lines are all suppressed both in oridonin and BEZ235 but not in vehicle control. That of $\mathrm{p}-\mathrm{AKT}^{\mathrm{High}}$ cell lines shows no significant suppression in all groups.

All possible results above are shown in Table 2. 
Table 2. Possible results of MTT, CCK-8, and Clonogenic growth assays

\begin{tabular}{|c|c|c|}
\hline MDAMD468、SKBR3 & $\begin{array}{c}\text { Possible } \\
\text { result 1 }\end{array}$ & $\begin{array}{c}\text { Possible } \\
\text { result 2 }\end{array}$ \\
\hline MTT &,+- &,-+ \\
\hline CCK8 &,+- &,-+ \\
\hline Clonogenic growth assays &,+- &,-+ \\
\hline
\end{tabular}

Note. " +" indicates that cell viability is suppressed by Oridonin and "-" means it is not suppressed by Oridonin.

\subsection{Western blotting}

\subsubsection{Possible result 1:}

Oridonin doesn't suppress phosphorylation of AKT1 neither. However, phosphorylation of AKT1 substrates (PRAS40, also called AKTS1) and downstream signaling protein S6RP are both suppressed.

\subsubsection{Possible result 2}

Oridonin has little effect on phosphorylation of AKTS1 and S6RP in MDAMB468 but suppresses them effectively in SKBR3. AKT1 isn't suppressed neither.

\subsubsection{Possible result 3}

Oridonin suppresses phosphorylation effectively of PRAS1 and S6RP in MDAMB468, but have little effect on SKBR3.AKT1 isn't suppressed neither.

All possible results are shown in Table 3.

Table 3. Possible results of Western blot

\begin{tabular}{|l|c|c|c|c|}
\hline $\begin{array}{l}\text { SKBR3 } \\
\text { MDAMD468 }\end{array}$ & AKT & AKT1 & PRAS40(AKTS1) & S6RP \\
\hline $\begin{array}{c}\text { Possible } \\
\text { result 1 }\end{array}$ &,-- &,-- &,++ &,++ \\
\hline $\begin{array}{c}\text { Possible } \\
\text { result 2 }\end{array}$ &,-- &,-- &,+++ &,+++ \\
\hline $\begin{array}{c}\text { Possible } \\
\text { result 3 }\end{array}$ &,-- &,-- &,+++ &,+++ \\
\hline
\end{tabular}

Note. " +" indicates that the phosphorylation of the protein is suppressed by Oridonin and "-" means it is not suppressed by Oridonin. " + +" shows better effect than " + ". AKT1 is a kind of substrates of AKT, and PRAS40 (AKTS1) is also called AKT1 substrate 1.S6RP is a kind of AKT downstream mTOR signaling proteins.

\subsection{Xenograft studies}

\subsubsection{Possible result 1}

The growth of tumors is both equally suppressed, but oridonin is not as effective as BEZ235.

\subsubsection{Possible result 2}

The growth of tumors is both equally suppressed, and oridonin is better than BEZ235.

\subsubsection{Possible result 3}

The growth of tumors is both suppressed. Oridonin suppresses tumors' growth in SKBR3 not better than BEZ235, but suppresses it in MDAMD468 better than BEZ235.

\subsubsection{Possible result 4}

The growth of tumors is both suppressed. Oridonin suppresses tumors' growth in MDAMD468 not better than BEZ235, but suppresses it in SKBR3 better than BEZ235.

All possible results above are also shown in Table 4.

Table 4. Possible results of Xenograft studies

\begin{tabular}{|c|c|c|}
\hline & $\begin{array}{c}\text { MDAMD468 } \\
\text { cells }\end{array}$ & SKBR3 cells \\
\hline $\begin{array}{c}\text { Possible } \\
\text { result 1 }\end{array}$ & + & + \\
\hline $\begin{array}{c}\text { Possible } \\
\text { result 2 }\end{array}$ & ++ & ++ \\
\hline $\begin{array}{c}\text { Possible } \\
\text { result 3 }\end{array}$ & ++ & ++ \\
\hline $\begin{array}{c}\text { Possible } \\
\text { result 4 }\end{array}$ & + & + \\
\hline
\end{tabular}
Oridonin. " + +" shows tumors' growth is suppressed by Oridonin better than by BEZ235.

\section{Discussion}

Oridonin is reported to be an AKT1 inhibitor. Thus it can suppress PI3K/AKT signaling, for which it can inhibit p-AKT ${ }^{\text {High }}$ breast cancers.

\subsection{MTT, CCK-8, and Clonogenic growth assays}

Possible result 1 follows the hypothesis, indicating that Oridonin only has an effect on $\mathrm{p}-\mathrm{AKT}^{\text {High }}$ breast cancer. Therefore, further studies like western blotting can be performed.

Possible result 2 totally contracts with the hypothesis. It shows that Oridonin only suppresses p-AKT ${ }^{\text {Low }}$ breast cancer. Since this is contrary to Oridonin's therapeutic mechanism, it is unlikely to happen.

\subsection{Western blotting}

Possible result 1 shows Oridonin only suppresses phosphorylation of AKT1 substrates and downstream molecule but not AKT1. Thus, Xenograft studies can be performed [11] [12].

Possible results 2 and 3 indicate Oridonin has a 
preference. Possible result 2 shows Oridonin is more effective on HER2 amplification $\mathrm{p}-\mathrm{AKT}^{\mathrm{High}}$ breast cancer. However, possible result 3 indicates that Oridonin is better for PTEN loss breast cancer. More studies will be required to discover which one is true.

\subsection{Xenograft studies}

Possible results 1, 2, 3, 4 verify the hypothesis. Possible result 1 indicates Oridonin is not as effective as BEZ235. If further studies indicate Oridonin is much cheaper or less toxic than BEZ235, it still has some value. Possible result 2 shows the best result. Oridonin can be further researched in clinical trial.

Possible results 3 and 4 prove Oridonin has a preference between HER2 amplification and PTEN loss inducing breast cancers. The mechanism needs to be further studied.

\section{Conclusion}

The experiment has studied the therapeutic effect of Oridonin through Clonogenic growth, MTT, CCK-8 assays, western blot, and xenograft studies. It not only focuses on the theraputic use of Oridonin on breast cancer, but also on PTEN loss and HER2 amplification p-AKT ${ }^{\text {High }}$ breast cancer. Before clinical trial, further studies need to focus on production cost and toxicity of Oridonin.

\section{References}

1. C. Criscitiello, G. Viale, G. Curigliano, A. Goldhirsch, Profile of buparlisib and its potential in the treatment of breast cancer: evidence to date, Breast Cancer (Dove Med Press) 10 (2018) 23-29.

2. M. Cully, H. You, A.J. Levine, T.W. Mak, Beyond PTEN mutations: the PI3K pathway as an integrator of multiple inputs during tumorigenesis, Nat Rev Cancer 6(3) (2006) 184-92.

3. B. Sun, G. Wang, H. Liu, P. Liu, W.O. Twal, H. Cheung, S.L. Carroll, S.P. Ethier, E.E. Mevers, J. Clardy, T. Roberts, C. Chen, Q. Li, L. Wang, M. Yang, J.J. Zhao, Q. Wang, Oridonin inhibits aberrant AKT activation in breast cancer, Oncotarget 9(35) (2018) 23878-23889.

4. N.E. Hynes, H.A. Lane, ERBB receptors and cancer: the complexity of targeted inhibitors, Nat Rev Cancer 5(5) (2005) 341-54.

5. K. Stemke-Hale, A.M. Gonzalez-Angulo, A. Lluch, R.M. Neve, W.L. Kuo, M. Davies, M. Carey, Z. Hu, Y. Guan, A. Sahin, W.F. Symmans, L. Pusztai, L.K. Nolden, H. Horlings, K. Berns, M.C. Hung, M.J. van de Vijver, V. Valero, J.W. Gray, R. Bernards, G.B. Mills, B.T. Hennessy, An integrative genomic and proteomic analysis of PIK3CA, PTEN, and AKT mutations in breast cancer, Cancer Res 68(15) (2008) 6084-91.

6. T.L. Yuan, L.C. Cantley, PI3K pathway alterations in cancer: variations on a theme, Oncogene 27(41) (2008) 5497-510.

7. C.E. DeSantis, J. Ma, A. Goding Sauer, L.A. Newman, A. Jemal, Breast cancer statistics, 2017, racial disparity in mortality by state, CA Cancer $\mathrm{J}$ Clin 67(6) (2017) 439-448.

8. M. Paryan, R. Tavakoli, S. Rad, N. Feizi, F. Kamani, E. Mostafavi, S. Mohammadi-Yeganeh, Over-expression of NOTCH1 as a biomarker for invasive breast ductal carcinoma, 3 Biotech 6(1) (2016) 58.

9. J.A. Engelman, Targeting PI3K signalling in cancer: opportunities, challenges and limitations, Nat Rev Cancer 9(8) (2009) 550-62.

10. W. Kalt, D.A. Ryan, J.C. Duy, R.L. Prior, M.K. Ehlenfeldt, S.P. Vander Kloet, Interspecific variation in anthocyanins, phenolics, and antioxidant capacity among genotypes of highbush and lowbush blueberries (Vaccinium section cyanococcus spp.), J Agric Food Chem 49(10) (2001) 4761-7.

11. T. Fujita, Y. Takeda, H.D. Sun, Y. Minami, T. Marunaka, S. Takeda, Y. Yamada, T. Togo, Cytotoxic and antitumor activities of Rabdosia diterpenoids, Planta Med 54(5) (1988) 414-7.

12. T. Ikezoe, S.S. Chen, X.J. Tong, D. Heber, H. Taguchi, H.P. Koeffler, Oridonin induces growth inhibition and apoptosis of a variety of human cancer cells, Int J Oncol 23(4) (2003) 1187-93. 